\title{
Correction to: Analytical Description of the Influence of the Welding Parameters on the Hot Cracking Susceptibility of Laser Beam Welds in Aluminum Alloys
}

CHRISTIAN HAGENLOCHER, DANIEL WELLER, RUDOLF WEBER, and THOMAS GRAF

https://doi.org/10.1007/s11661-019-05542-0

(C) The Minerals, Metals \& Materials Society and ASM International 2019

Correction to:

Metallurgical and Materials Transactions A,

Volume 50A, November 2019

https://doi.org/10.1007/s11661-019-05430-7

IN the original article the indefinite integral sign of the solidification path is missing in Eq. [5].

The correct representation of Eq. [5] is:

$$
\dot{\varepsilon}_{\mathrm{RDG}}=\frac{\Delta p_{\mathrm{c}}-v_{\mathrm{T}} \cdot \beta \cdot \mu \cdot \int_{x_{\mathrm{coh}}}^{x_{\mathrm{L}}} \frac{1-f_{\mathrm{S}}(x)}{K(x)} \mathrm{d} x}{(1+\beta) \cdot \mu \cdot \int_{x_{\mathrm{coh}}}^{x_{\mathrm{L}}} \frac{\int f_{\mathrm{S}}(x) \mathrm{d} x}{K(x)} \mathrm{d} x}
$$

CHRISTIAN HAGENLOCHER, DANIEL WELLER, RUDOLF WEBER, and THOMAS GRAF are with the Institut für Strahlwerkzeuge, University of Stuttgart, Pfaffenwaldring 43, 70569 Stuttgart, Germany. Contact e-mail: christian.hagenlocher@ifsw.unistuttgart.de

The original article can be found online at https://doi.org/10.1007/ s11661-019-05430-7.

Article published online November 5, 2019
The rest of the paper is not affected by this correction. The results and diagrams in the paper were calculated with the correct equation (including the indefinite integral of the solidification path) and are therefore correct.

Publisher's Note Springer Nature remains neutral with regard to jurisdictional claims in published maps and institutional affiliations. 